\title{
0 início das idéias socialistas no Brasil
}

Daniela Oliveira R. Passos ${ }^{1}$

Resumo: O presente trabalho procura analisar como se deu a organização das idéias socialistas no Brasil no final do século XIX e início do século XX (1889-1922) e como estas ideologias marcaram o movimento operário da "República Velha". Para tanto, será conceituado os termos usados pelos movimentos sociais trabalhistas do período, além de especificar cronologias e tentar perceber como o contexto mundial da época influenciava em terras nacionais.

Palavras-chaves: socialismo, anarquismo, social democracia, Estado, trabalhadores.

Abstract: The present text seeks to analyse how socialist ideas were organized in Brazil at the end of the nineteenth century and early twentieth century (1889-1920) and how these ideologies marked the labour movement in the "Old Republic". Therefore, the terminology used by the social labour movements will be denominated, and chronologies will be specified. Besides, we will try to understand how the word context of the time influenced Brazil as a nation.

Keywords: socialism, anarchy, social democracy, State, workmen.

\section{Os Ideais reformistas (1889 - 1905)}

O socialismo, tal como é entendido hoje, entra na história em meados do século XVIII. Seu contexto histórico é marcado pela Revolução Industrial, que traz consigo, além do progresso capitalista, uma jornada de trabalho de 14 horas, as conseqüências do cercamento (enclosures) ${ }^{2}$, os salários baixos, o trabalho explorador de mulheres e

1 Mestranda pela Universidade Federal de Ouro Preto. Correio eletrônico: ddanipassos@gmail.com

2 "A Lei das Cercas" (enclosure act) foram as demarcações realizadas no antigo "sistema de campos abertos" (open field system) ingleses e se tornaram um dos elementos fundamentais para a Inglaterra iniciar a Revolução Industrial. Com as cercas, desaparece a lavoura e se desenvolve a pecuária, sobretudo a criação de ovelhas, sendo estas as fornecedoras de matéria-prima para as máquinas industriais. Para Iglesias (1987, p. 49) é neste período que se alterou o modo de produção existente. Surgiu o capitalismo, decorrente da grande indústria.

cadernos cemarx, $\mathrm{n}^{\mathrm{O}} 5-2009 \quad 115$ 
crianças e a inexistência das mínimas condições de sobrevivência. Portanto, segundo Spindel (1995, p. 15), as idéias socialistas são conseqüências da miséria reinante, são os apelos de uma população a procura de sua dignidade humana. Para Engels (1971, p. 47) ele é fruto dos antagonismos de classe que reinam na sociedade moderna entre "possuidores e despossuidos, capitalistas e operários assalariados".

Pianciola (2000, p. 1196-7) refere-se ao socialismo como um conjunto de doutrinas que se propõe a promover o bem comum pela transformação da sociedade, ou seja, mudança nas ordens jurídica e econômica. A proposta socialista é que o direito de propriedade seja limitado, os principais recursos econômicos estejam sob o controle da classe trabalhadora e seu comando tenha por meta a igualdade social.

Assim, dentro deste conjunto de doutrinas encontramos uma gama de soluções, conceitos e propostas diferenciados, mas que procuram o mesmo fim.

No Brasil, a grande esperança da classe trabalhadora ${ }^{3}$ surgiu com o advento da República (1889) que, segundo o operariado organizado, trazia a igualdade dos direitos políticos e sociais. Dentro deste regime - de ordem e progresso - o trabalho não era mais sinal de atraso e infortúnio, como acontecia no período monárquico com a mão-de-obra escrava. $\mathrm{O}$ trabalho e aqueles que trabalhavam - o proletário - eram a força essencial da sociedade, seu elemento de prosperidade, riqueza e progresso (GOMES, 2005, p. 40).

Porém, esta expectativa do trabalhador foi "quebrada", na medida em que o regime republicano se mostrou incapaz de atender aos anseios da classe operária, sugerindo projetos pouco nítidos de igualdade e democracia.

Esta “desesperança”, segundo Batalha (2003, p. 174) ocasionou duas respostas dadas pelo movimento operário brasileiro: a primeira, (no contexto dos anos de 1890 a 1905), propunha a conquista dos direitos sociais aliada aos direitos políticos, ou seja, visava à mudança do sistema pela participação no processo eleitoral ${ }^{4}$.

Esta resposta partia da premissa de que a ação política era o principal meio de luta, tendo como instrumento o partido operário, já que a revolução pregada pelos

\footnotetext{
3 Trabalharemos o conceito de classe utilizado por Thompson, que afirma que: “(...) quando alguns homens, como resultado de experiências comuns (herdadas ou partilhadas), sentem e articulam a identidade de seus interesses entre si, e contra outros homens cujos interesses diferem (e geralmente se opõem) dos seus. A experiência de classe é determinada, em grande medida, pelas relações de produção em que os homens nasceram - ou entraram involuntariamente. A consciência de classe é a forma como essas experiências são tratadas em termos culturais: encarnadas em tradições, sistemas de valores, idéias e formas institucionais" (THOMPSON, 1989, p. 10).

4 O programa do partido operário brasileiro de 1893 justifica seu lançamento no seguinte argumento: "a emancipação econômica da classe trabalhadora é inseparável de sua emancipação política” (MORAES FILHO,1998, p. 404).

\begin{tabular}{l|l} 
& O início das idéias socialistas no Brasil
\end{tabular}
} 
anarquistas era vista como "estéril" e "derramaria sangue inútil" em jornadas de muita luta.

O operário devia ser político mesmo reconhecendo que a República não fora geradora

do progresso e da igualdade que ele esperava. Por isso era necessário ter representantes no Parlamento, os quais, mesmo em minoria, trariam maior respeito e atenção para os reclamos operários (GOMES, 2005, p. 68).

Assim, segundo os operários, se eles se organizassem em torno de um partido, sua ação nas urnas deveria ser mais benéfica do que tentar utopicamente mudar, através da força, as instituições então estabelecidas. Portanto, "é no terreno político que os operários tinham que dar batalha" (BATALHA, 1995, p. 16).

Estas idéias são características do aumento no número de votos dos partidos operários e socialistas europeus, que eram vistos como um prenúncio da instauração do socialismo.

Na Alemanha, o partido socialista já era, em 1890, o maior partido com $19,7 \%$ dos votos e em 1912 atingiu o dobro relativo ao segundo maior partido, 34,8\%. Na Finlândia, em 1907, quando da primeira eleição com sufrágio universal, os social-democratas conseguiram a maioria relativa, com $37 \%$ dos votos. Assim também ocorreu na Bélgica, na religiosa Holanda, na Dinamarca, na Suécia e na Noruega (ALMEIDA, 2003, p. 190.).

Batalha (2003, p. 175) ainda cita que os socialistas brasileiros transportavam para a República o mesmo raciocínio empregado pelos socialistas europeus para a Revolução Francesa, o de que tanto uma como a outra seriam processos iniciados, porém incompletos, cabendo ao socialismo levá-los adiante.

Um dos precursores deste ideal é o francês Graco Babeuf que, liderando a Conspiração dos Iguais ${ }^{5}$, pregava não só a igualdade política, mas também a econômica. Ele afirmava que era essencial que o povo se organizasse e lutasse para que a "Liberdade, Igualdade e Fraternidade" - ideais da Revolução Francesa - existissem para todos.

(...) a natureza conferiria a cada homem o direito igual de desfrutar de tudo o que

5 Movimento dos sans-culottes que ocorreu em 1796, dentro da fase do Diretório (Revolução Francesa).

cadernos cemarx, $\mathrm{n}^{\circ} 5-2009 \quad 117$ 
é bom, e o objetivo da sociedade era defender esse direito; que a natureza impusera a cada homem o dever de trabalhar, e quem dele se esquivava era um criminoso; que o objetivo da Revolução (Francesa) fora acabar com todas as desigualdades e estabelecer o bem-estar de todos; que a Revolução, portanto, não estava terminada, e os que haviam abolido a Constituição de 1793 (Ano I) eram culpados de lesa-majestade contra o povo (WILSON, 1986, p. 73-4).

Desta forma, os reformistas brasileiros buscavam não só os direitos sociais, mas também a emancipação nos direitos políticos. Batalha (2003, p. 174) relata que no sistema vigente, após a proclamação da República, votavam apenas homens, brasileiros, maiores de vinte e um anos, alfabetizados. Já os programas dos partidos operários brasileiros propunham a eleição direta para todos os cargos e o sufrágio universal.

Os partidos de gênero socialista/comunista se multiplicaram neste período. Houve mais ou menos vinte partidos de cunho social, entre os anos de 1890 e 1920 , "sem raízes": criados, viviam meses, um ou dois anos e desapareciam. De fato, a sociedade não os compreendia e nem ajudava na sua criação e permanência, pois os partidos não tinham muito a ver com o real, representando mais desejos utópicos ou simples influência de leitura do que estava acontecendo na Europa (IGLÉSIAS, 1993, p. 219).

O motivo de os ideais socialistas, na virada do século XX no Brasil, serem de cunho socialdemocrata se explica, segundo GOMES (2005, p. 36), pelo contexto histórico brasileiro da época (governo provisório) ser de instabilidade política, pois com o advento da República houve a possibilidade de uma nova constituição dos "atores políticos" e uma redefinição dos instrumentos formais de participação. Era como se o "poder" estivesse aberto às novas idéias e às novas propostas de organização.

Portanto, o fundamento na formação de um partido operário se pautava na "valorização do trabalho e do trabalhador e na crença da possibilidade de os direitos operários serem definidos dentro das regras do sistema representativo" (GOMES, 2005, p. 41).

Assim, o momento político em que se vivia era o mais propício para que as classes operárias fizessem valer seus direitos e estabelecessem sua pretensão de representação junto a futuros governos.

Para os trabalhadores do final do século XIX, as reformas sociais desejadas somente poderiam vir através das leis e estas só se fariam com a existência de mais

\begin{tabular}{l|l}
\hline 118 & O início das idéias socialistas no Brasil
\end{tabular} 
representantes das classes trabalhadoras.

As reivindicações e o programa adotado pelo partido operário brasileiro girava em torno da diminuição da jornada de trabalho (para oito horas diárias), fim do trabalho feminino e infantil, criação de "juntas arbitrárias" para mediar os conflitos entre empregados e empregadores, o amparo à velhice e a invalidez, além de reformas no Estado, como a educacional, fiscal e eleitoral.

Por partidos operários devem ser entendidos tanto as múltiplas organizações socialistas que surgem e desaparecem durante toda a Primeira República, quase sempre em função de alguma disputa eleitoral, como o conjunto dos socialistas que se situam no terreno da luta política. É até plausível que a própria instabilidade e vida curta das organizações criadas contribuíam para que a designação de "partido operário" seja empregada frequentemente para um campo político ao invés de remeter a uma organização específica; mesmo na França de fins de século XIX, o termo "partido operário" designava o conjunto das correntes socialistas divididas em várias organizações e grupos. (BATALHA, 1995, p. 17).

A evolução "natural" para o socialismo, também não eliminava a ação organizativa, como greves e procedimentos por vezes conflitantes com o patronato em geral e com o governo republicano e suas medidas econômico-sociais nada democráticas. Porém, o ponto central dos reformistas brasileiros do final do século XIX, eram as vitórias graduais no parlamento e "dentro de um espírito de moderação" (GOMES, 2005, p. 69).

Conclui-se que o ideal socialista do movimento operário brasileiro entre os anos de 1890 a 1905 era o de lutar contra a República instaurada e o mandonismo do patronato. Não há um ideário (pelo menos no primeiro momento) de uma revolução e da conseqüente derrubada do Estado, como pregavam Marx e Engels. ${ }^{6}$

\section{A força do anarquismo (1906-1917)}

A perspectiva de um "movimento socialista" de mudança pela via parlamentar foi perdendo força à medida que greves no interior de algumas fábricas

6 Num primeiro momento, através da revolução - que ocorreria por causa do fatal processo histórico (modo de produção feudal, relações capitalistas de produção, socialismo e comunismo) e da gradual consciência de classe por parte dos trabalhadores - seria instalado o controle do Estado pela ditadura do proletariado e a socialização dos meios de produção, eliminando a propriedade privada. Numa etapa posterior, a meta seria o comunismo, que representaria o fim das desigualdades sociais e econômicas, inclusive o próprio Estado (SPINDEL, 1995, p. 39-40).

cadernos cemarx, $\mathrm{n}^{\circ} 5-2009 \quad 119$ 
se generalizaram. Eram movimentos espontâneos, como a greve dos sapateiros (19021903) e a greve dos industriais têxteis (início 1903), ambas ocorridas na cidade do Rio de Janeiro. Estes operários reivindicavam melhores condições de trabalho, aumento salarial, redução da jornada de labor, habitações operárias e escolas, auxílio aos desempregados e o combate ao uso de bebidas alcoólicas e ao jogo (GOMES, 2005, p. 72). A cidade do Rio presenciou uma grande greve, que aconteceu em agosto e setembro de 1903 e mobilizou os operários têxteis, pedreiros, alfaiates, estivadores, sapateiros, chapeleiros, pintores, entre outros.

Desta forma, as greves tiveram início por questões específicas de cada setor. A generalização dos protestos, para outras fábricas (não têxteis) e para oficinas de gênero diverso, ocorreu devido à insatisfação de alguns trabalhadores com a não concretização das propostas dos partidos operários ${ }^{7}$ e à descrença com o poder público.

Além disso, outro fator apresentado por Gomes $(2005$, p. 74) é a conjuntura política. Após 1906, o quadro político-administrativo foi "definitivamente" estabelecido no país, através da "política dos governadores", montada pelo então presidente Campos Sales. Assim, o "poder" já não estava mais disposto a se abrir para novos ideais.

Portanto, a segunda resposta dada pelo movimento operário brasileiro à República então instaurada (nada democrática e igualitária) foi a negação da política institucional, adotando a "ação direta" " como forma de pressão para obter as conquistas necessárias. Estes operários socialistas dos anos de 1906 a 1922 não viam nas práticas eleitorais e parlamentares a possibilidade de transformar a sociedade. Para eles, seria seguindo o método da ação direta, particularmente expressa em movimentos grevistas, que o sindicalismo operário poderia alcançar a emancipação dos trabalhadores (BATALHA, 2003, p. 179).

$\mathrm{O}$ anarquismo, num sentido amplo, prega que a liberdade e a igualdade só seriam conseguidas quando o capitalismo e o Estado - que o defende - fossem

\footnotetext{
7 Lembrando que os partidos operários da Primeira República tinham duração efêmera e quase sempre eram expressivos apenas em âmbito local.

8 A ação direta é um conceito de maturidade frente a um conceito de infantilismo, pelo qual o homem desiste de suas responsabilidades e a delega a outros, a seus representantes, abstendo-se de fazer pensar por sua conta e risco (COSTA, 1980, p. 20). Portanto, a ação direta é aceitar todas as responsabilidades com todas as conseqüências, sem delegá-las a um terceiro; auto gerir-se; rejeitar os intermediários, os mediadores. Dentro do contexto brasileiro da primeira Republica, rejeitar os partidos políticos, ou representantes do governo.

\begin{tabular}{l|l}
\hline 120 & O início das idéias socialistas no Brasil
\end{tabular}
} 
destruídos. Como o socialismo, o anarquismo considera a propriedade privada como a fonte principal dos problemas sociais. Argumenta ainda que todos os recursos naturais da terra pertencem a todos os homens. Assim, a palavra anarquista, em sentido "científico" significa valorizar o indivíduo, este sem representantes, sem delegações, sem Estado. Liberdade é seu principio.

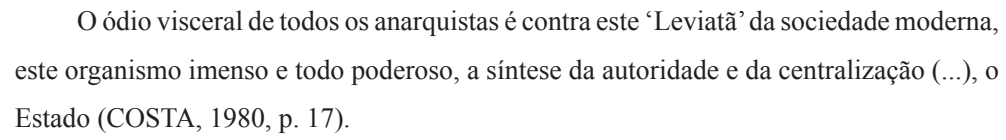

No Brasil, os anarquistas acreditavam que a única forma do movimento operário conquistar seus direitos era afastar a política de caráter eleitoral, partidária, e parlamentar, de seu interior, pois a considerava totalmente indiferente aos seus propósitos (GOMES, 2005: 83). Os trabalhadores anarquistas rejeitavam o partido político e as suas propostas. A estratégia revolucionária anárquica pregava a luta política através das greves e da educação da classe trabalhadora. Para eles, a revolução somente ocorreria se houvesse uma transformação profunda no homem trabalhador. O que os anarquistas almejavam era uma revolução social e não política, daí privilegiar a educação, para formar "sujeitos sócio-culturais" e conscientes de seus direitos.

Desta forma, o que distingue os anarquistas das demais correntes que lutavam pela "libertação" dos trabalhadores é a sua ação. Um dos métodos de luta anarquista era a admissão do emprego da força como resistência à violência capitalista, incutida no governo e no patronato em geral. Contudo, segundo afirma Gomes (2005, p. 90), aceitar o emprego de ações violentas não significava rejeitar a utilização de ações pacíficas e, sobretudo, não significava utilizar somente o "terrorismo". Uma greve poderia ser empregada tanto como um expediente de resistência e defesa pacífica como uma forma mais impositiva e violenta de realizar conquistas (IDEM, p. 91).

Portanto, a prática dos anarquistas não se pautava apenas pelo uso da força, que por ventura empregavam, mas pelo repúdio pelos processos políticos, por via de partidos parlamentares ou ações eleitorais. A organização, segundo eles, surgia in locus, e ali se enfrentavam "face a face", patrões e empregados, sem necessitar de interlocutores.

Os trabalhadores anarquistas brasileiros se espelhavam no que estava ocorrendo na Europa para refletir sobre as ações eleitorais. Na Alemanha e em Portugal já se observava que os socialistas reformistas acabaram sujeitos ao parlamento e

cadernos cemarx, $\mathrm{n}^{\mathrm{O}} 5-2009 \quad 121$ 
muitos terminavam até criticando o próprio ideário socialista.

Em decorrência de sua situação de minoria parlamentar, as reformas propostas pelos partidos socialistas eram apenas aquelas que garantiam a continuidade do funcionamento da economia nos moldes capitalistas e que não alteravam o equilíbrio político das forças sociais (ALMEIDA, 2003, p. 192)

Assim, a força política anarquista se restringia a pressionar diretamente os "dominadores", através de conversas, debates, boicotes, sabotagens, denúncias, greves e levantes, realizados através da "ação direta", ou seja, o intuito era atuar mais próximo aos operários.

O marco da ascensão anarquista entre os trabalhadores brasileiros é o I Congresso Operário, realizado na cidade do Rio de Janeiro em 1906. As resoluções desse Congresso rejeitavam a formação de um partido político e condenavam as forças de organização como cooperativas. No Brasil, a opção anarquista privilegiava o sindicato, ou seja, aqui prevaleceu o anarco-sindicalismo. Os anarco-sindicalistas acreditavam que os sindicatos poderiam ser utilizados como instrumento para mudar a sociedade, substituindo o capitalismo e o Estado por uma nova sociedade democraticamente auto-gerida pelos trabalhadores.

Porém, mesmo tendo graves defeitos, como o autoritarismo (pois quanto mais forte e burocrático mais conservador tendia a ficar), o sindicato foi considerado pelos anarquistas brasileiros o meio mais propício para realizar reuniões, preparar e ampliar o número de trabalhadores conscientes e preocupados com seus direitos.

O sindicato profissional era um campo fértil para semear idéias e permitir que os anarquistas entrassem em contato com os trabalhadores, ganhando assim sua confiança e adesão. Esta proximidade era essencial para afastar o proletário dos 'parasitas' da política e, através da ação orientada sobre o terreno econômico, conduzi-los a revolução social, e não somente a revolução política (GOMES, 2005, p. 94.).

Assim, os anarco-sindicalistas apoiavam o sindicato, mas não pretendiam que ele fosse o "microcosmo" da sociedade, pois o anarquismo, em sua doutrina, afirma que em uma sociedade todos são livres, porque participam de forma igualitária de um projeto associativo, cumprindo-se a promessa de harmonia entre a vontade de todos e a vontade de cada um.

As reivindicações e o programa adotado pelo Congresso de 1906 (ano em

\begin{tabular}{l|l}
\hline 22 & O início das idéias socialistas no Brasil
\end{tabular} 
que os anarquistas se propuseram a criar os sindicatos) previam a redução das horas de trabalho, que tem influência direta sobre a necessidade do bem-estar do trabalhador, facilitando ainda o estudo, a educação e a emancipação intelectual; o combate ao alcoolismo, que era fruto do excesso de trabalho; a abolição das multas nas oficinas e fábricas; o direito de reunião, a fim de defender os direitos dos trabalhadores; criação de escolas; indenização por acidentes de trabalho; criação de asilos ou meios para beneficiar operários inválidos; regulamentação do trabalho feminino e construção de casas operárias (PINHEIRO \& HALL, 1979, p. 51-54).

Segundo Gomes (2005: 118) a ascensão do movimento dos libertários (anarquistas) se dividiu em duas fases. Num primeiro momento (1906-1917), os militantes anarquistas se envolveram em uma série de ações, nas quais as greves não predominavam, mas sim ampla propaganda sobre formas de mobilização e ideologia do movimento anarquista; propaganda que era divulgada através de crescente número de periódicos anarquistas, numerosas campanhas sobre o movimento com o intuito de influenciar as associações operárias já existentes e a criação de novas associações sindicais anarquistas. Houve ainda a organização de ligas anticlericais e antimilitaristas, além da criação do Centro de Estudos Sociais (1914), que se constituiu num foro de debates entre socialistas e anarquistas.

A partir de 1917 até 1920, há um número maior de greves e menor de propaganda sobre a ideologia anarquista. Isto devido à eclosão da Primeira Guerra Mundial, que afetou profundamente a economia do país e a vida dos trabalhadores, devido à escassez dos produtos industrializados vindos da Europa, o que ocasionou a conseqüente falta de alimentos no mercado interno, a elevação dos preços dos gêneros de primeiras necessidades e o aumento dos aluguéis.

Nota-se também um número maior de anarquistas dentro das organizações de trabalhadores e a mudança significativa de associações em sindicatos. Neste período, percebe-se ainda que os "libertários" colocam mais força em suas propostas e passam a ganhar maior espaço público e a entrar em confronto aberto com a polícia e o patronato 9 .

9 "Os anarquistas passaram a promover grandes reuniões, voltadas para a propaganda de seu ideário, como comícios e festivais realizados ao "ar livre". Nestas festas havia o discurso doutrinário, recreações, bailes e partidas de futebol. O caráter lúdico atraia um público maior com o objetivo de conseguir recursos para o financiamento dos jornais anarquistas ou para o auxílio a famílias de lideres presos" (HARDMAN, Francisco Foot, Nem pátria, nem patrão: vida operária e cultura anarquista no Brasil. São Paulo: Brasiliense, 1984 apud GOMES, 2005, p. 122-23).

cadernos cemarx, $\mathrm{n}^{\circ} 5-2009 \quad 123$ 


\section{O socialismo de influência Russa: O Estado e o movimento operário (1918-1922)}

Os anos de 1919 a 1921 são usualmente apontados como o momento de declínio do movimento libertário. A conjuntura política que "se abria" era a de combate ao anarquismo. Dentro deste contexto houve um "amadurecimento" do conjunto de alianças contrárias ao movimento que reuniu polícia, patrões, elite política e intelectual e Igreja. Houve também a concorrência com associações profissionais patrocinada pelos empresários e pelo governo. Segundo Munakata (1981, p. 22), os sindicatos não anarquistas mantinham serviços regulares de beneficência com a participação do Estado. Eram prestados serviços médicos, auxílios farmacêuticos e pensão para os inválidos; e em 1919 alguns empregadores privados anunciavam a concessão "espontânea" da jornada de trabalho para oito horas.

O governo já fazia uma mudança no discurso, reconhecendo que era preciso "aperfeiçoar" a legislação social de forma a harmonizar os interesses do capital e do trabalho, como pode ser percebido na segunda candidatura de Rodrigues Alves, em 1918 (MARAM, 1979:, p.139). Assim, a intervenção estatal começou a ser solicitada, ou seja, as reivindicações como a jornada de trabalho de oito horas, a regulamentação do trabalho feminino e infantil, entre outras, apontam para a elaboração de leis sobre o assunto. Também havia o medo da revolução (como a ocorrida na Rússia em 1917) e a ameaça de uma outra guerra (como a Primeira Guerra Mundial, 1914-1918) que fizeram com que as idéias liberais perdessem força. Para Munakata (1981, p.32), em nome da harmonia social e da paz entre os povos, as leis trabalhistas deveriam ser reguladas, coordenadas e fiscalizadas pelo Estado.

A competição ideológica com o socialismo também se tornou mais acirrada, devido à vitória socialista na Revolução Russa (1917), fazendo com que essa doutrina voltasse a ter influência sobre os movimentos operários no Brasil. É importante frisar que o socialismo que passou a disputar a hegemonia com o anarquismo do pós-1920 era qualitativamente diferente do socialismo anterior, empregado pelo evolucionismo reformista. O socialismo deste contexto procede da teoria marxista-leninista, que busca o exercício direto do poder político através de um partido operário revolucionário e da conseqüente "ditadura do proletário" como forma de passagem para o comunismo. O Estado, neste caso, não seria abolido, mas extinto. Neste ponto, o conflito com a doutrina anarquista era total e claramente definido.

Nesta conjuntura, o anarquismo foi eleito o "perigo da década". Aliado aos

\begin{tabular}{l|l}
\hline 24 & O início das idéias socialistas no Brasil
\end{tabular} 
estrangeiros ${ }^{10} \mathrm{e}$ ateus, eram eles os inimigos a serem combatidos. Portanto, não houve um declínio de militância anarquista nos sindicatos, mas uma forte pressão ideológica - e no caso policial, prática - para por fim aos "libertários". O anarquismo havia sido definido como uma "ameaça a ordem constituída", devendo assim, ser eliminado por ação policial ${ }^{11}$.

Desta forma, devido à situação de "crise" nos meios sindicais do país, à precária situação da imprensa anarquista e ao Estado de Sítio, decretado pelo presidente Arthur Bernardes para tentar pôr fim às reivindicações operárias e ao movimento tenentista, o ideário anarquista tornou-se insustentável.

Em 1922 é fundado o Partido Comunista do Brasil (PCB), que logo passou para a ilegalidade. Mas antes de se tornar "clandestino", segundo Munakata (1981, p. 42), ele conseguiu ter influências em alguns sindicatos cariocas. A proposta do partido girava em torno de uma organização sindical centralista, capaz de por fim as "divergências" dentro do movimento operário ${ }^{12}$, o que se diferenciava do modelo descentralizado de sindicato proposto pelos anarquistas, cujo princípio era a autonomia.

Através de uma série de normas rigorosas e determinadas, o PCB organizava a luta dos trabalhadores. Lembrando que o partido sofria fortes influências do marxismo-leninismo, que além da utilização do poder de um Estado revolucionário para fins revolucionários, também:

esteve ativamente comprometido com a firme crença na superioridade da centralização sobre a descentralização ou federalismo e (especialmente em sua versão leninista) comprometido com a convicção de que liderança, organização e disciplina são indispensáveis, sendo inadequado qualquer movimento apoiado em mera “espontaneidade”. (HOBSBAWM, 1982, p. 68).

Além disto, mesmo tendo sido essencialmente repressiva, sob a presidência de Arthur Bernardes (1922-1926), os trabalhadores tiveram algo a "comemorar".

10 Lei Adolfo Gordo, ou Lei de Expulsão de Estrangeiros (Decreto ${ }^{\circ} 4.247$ de 6.1.1921) o projeto aprovado considerava o anarquismo crime e permitia legalmente à deportação de estrangeiros envolvidos em associações e "distúrbios" que fossem considerados prejudiciais a "ordem pública".

11 Associações operárias passaram a ser invadidas por policiais; comícios anarquistas foram proibidos e agentes policiais começaram a encontrar bombas espalhadas no centro da cidade do Rio de Janeiro e a atribuí-las a atos anarquistas (GOMES, 2005, p. 135).

12 Criação da Confederação Geral do Trabalho (CGT). Ele era o topo da "pirâmide" que abrangia tanto as federações sindicais territoriais (por Estado) como as federações nacionais de acordo com a categoria (MUNAKATA, 1981, p. 43). 
A plataforma política apresentada em 1921 agregava medidas legais de melhorias operárias como construção de casas populares, a regulamentação das condições de higiene e segurança no local de trabalho, entre outras.

Portanto, a significante presença do Estado, através das leis que "protegiam" os trabalhadores (ou como uma espécie de "ponte" para o comunismo, isto de acordo com o socialismo marxista), tornou as lutas anarquistas incoerentes; afinal, seria um "contra-senso" empregar o método anarquista de luta para fazer cumprir as leis. Sendo este um dos motivos da crise do movimento anárquico: eles não compreenderam a importância da conquista de uma legislação social, já que eram contra a intervenção estatal nas relações entre operários e patrões.

Também é importante salientar que, durante o Governo do presidente Arthur Bernardes, a mobilização dos trabalhadores se tornou reduzida, tendo desaparecido inúmeras associações de classe e escasseado as greves operárias (GOMES, 2005, p. 144).

Iniciou-se, assim, um período de grande repressão aos movimentos dos trabalhadores e ao mesmo tempo uma "intervenção estatal" mais ampla nos direitos e deveres do operariado.

Bibliografia

ALMEIDA, Cristiane de Castro e. "Da revolução à reforma: a trajetória histórica da social democracia". Cronos: Revista de História, Pedro Leopoldo, nº 7, p.183197, jul. 2003.

ARANHA, Maria Lúcia de Arruda; MARTINS, Maria Helena Pires. Filosofando: introdução à filosofia. São Paulo: Moderna, 1986, cap. 7: Ideologia, p. 70-87.

BATALHA, Cláudio H. M. "A difusão do marxismo e os socialistas brasileiros na virada do século XIX”. In: MORAES, João Quartim (Org.). História do marxismo no Brasil: os influxos teóricos. Campinas, SP: Editora da UNICAMP. Vol. 2, p.11-44, 1995.

BATALHA, Cláudio H. M. "Formação da classe operária e projetos de identidade coletiva". In: FERREIRA, Jorge; DELGADO, Lucilia de Almeida Neves (Org.). O Brasil republicano: o tempo do liberalismo excludente - da Proclamação da República à Revolução de 1930. Rio de Janeiro: Civilização Brasileira, p.163$189,2003$.

COSTA, Caio Túlio. O que é anarquismo. 15 ed. São Paulo: Brasiliense, 1980.

\begin{tabular}{l|l}
\hline 126 & O início das idéias socialistas no Brasil
\end{tabular} 
DULLES, John W. F. Anarquistas e comunistas no Brasil (1900-1935). Rio de Janeiro: Nova Fronteira, 1977.

ENGELS, Friedrich. Do socialismo utópico ao socialismo cientifico. Lisboa: Editora Estampa, 1971. (Coleção Teoria, $n^{0}$ 6).

ENGELS, Friedrich; MARX, Karl. O manifesto do Partido Comunista. 13 ed. Rio de Janeiro: Paz e Terra, 1998. (Coleção Leitura).

GOMES, Ângela de Castro. A invenção do trabalhismo. 3.ed. Rio de Janeiro: Fundação Getulio Vargas, 2005.

HOBSBAWM, Eric J. Revolucionários. Rio de Janeiro: Paz e Terra, 1982.

IGLÉSIAS, Francisco. A revolução industrial. 9 ed. São Paulo: Brasiliense, 1987.

IGLÉSIAS, Francisco. Trajetória política do Brasil: 1500-1964. São Paulo: Cia das Letras, 1993.

MARAM, Sheldon L. Anarquistas, imigrantes e movimento operário brasileiro: 1880-1920. Rio de Janeiro; São Paulo: Paz e terra, 1979, vol .6.

MORAES FILHO, Evaristo de. O socialismo brasileiro. Brasília: Instituto Teotônio Vilela, 1998.

MUNAKATA, Kazumi. A legislação trabalhista no Brasil. São Paulo: Brasiliense, 1981.

PIANCIOLA, Cesare. "Socialismo”. In: BOBBIO, N.; MATTEUCCI, N.; PASQUINO, G. dicionário de política. 5.ed. Brasília: Editora UNB, vol 2, p. 1196-1202, 2000 .

PINHEIRO, Paulo Sergio de M. S.; HALL, Michael M. A classe operária no Brasil: documentos (1889-1930). São Paulo: Alfa Omega, 1979, vol.6.

SPINDEL, Arnaldo. O que é socialismo. 26 ed. São Paulo: Brasiliense, 1995. (Primeiros Passos, 1).

STOPPINO, Mário. Ideologia. In: BOBBIO, Norberto; MATTEUCCI, Nicola; PASQUINO, Granfranco. Dicionário de política. 5 ed. Brasília: Editora UNB, 2000. Vol 1, p.585-597.

WILSON, Edmund. Rumo à estação Finlândia. São Paulo: Cia das Letras, 1986.

\begin{tabular}{l|l} 
cadernos cemarx, $\mathrm{n}^{\mathrm{0}} 5-2009$ & 127
\end{tabular} 